\section{EL IMPACTO DE LOS DESASTRES: UNA OPORTUNIDAD PARA CRECER O DESAPARECER}

Víctor Orellana Acuña ${ }^{1,2, *}$

\section{INTRODUCTION}

Durante los años 80, la ciudad de Kobe ostentaba el lugar número 4 en el ranking de los puertos más grandes del mundo, solamente superado por New York, Rotterdam y Hong Kong. Se trataba de una ciudad importante dentro de Japón desde el punto de vista de su capacidad de transferencia de carga desde América hacia el interior de Asia y viceversa, dándole una identidad nacional y global. El terremoto de Hanshin-Awaji del 17 de Enero de 1995 significó un duro golpe para esta ciudad y para Japón, con pérdidas humanas de más de 7.000 personas y una caída del Producto Interno Bruto (PIB) de un 2,5\% en ese año. Durante los meses posteriores al desastre, el desempleo en la zona afectada llegó al $80 \%$, desapareciendo alrededor de 2.000 pequeñas y medianas empresas. A Enero de 1995 la población de la ciudad de Kobe ascendía a 1.520.365 habitantes, y en Octubre del mismo año descendió a 1.420 .000 personas.

Finalmente, al momento de iniciar la recuperación post desastre, sólo un 3\% de las instalaciones portuarias contaba con un seguro ante catástrofes, lo cual retrasó el proceso de reconstrucción final por más de dos años. Esta demora del Puerto de Kobe en re-incorporarse a la dinámica económica nacional y global significó una baja ostensible en su nivel de competitividad en una zona que ya entraba con fuerza al siglo XXI, quedando situada -al final del proceso de reconstrucciónubicada en el lugar 53 del mundo y 5 en Japón, muy por debajo de los mega-puertos chinos (estadísticas 2012 del Ministerio de Tierra, Infraestructura, Transporte y Turismo de Japón). No obstante lo anterior, este 'rezago' no debe entenderse como causado por una gestión deficiente, sino más bien como parte de una decisión estratégica que entendió el proceso de reconstrucción post terremoto de 1995 como una oportunidad de tomar una decisión sobre cuál sería la identidad del Nuevo Kobe: Una ciudad creativa, moderna y cosmopolita, y una ciudad segura y preparada para enfrentar nuevos desastres (Plan Fénix para la Reconstrucción de Kobe, 1995). Hoy en día, Kobe mantiene su calidad de ciudad portuaria, seguramente sin los bríos de la década de los años 80 , sin embargo se reconoce el gran desarrollo que le permite ser una de las ciudades más amables para vivir actualmente en Japón.

\section{DESARROLLO}

Los grandes desastres son también una oportunidad para que las ciudades, sus líderes y sus comunidades puedan decidir qué futuro quieren construirse, sin embargo en muchas ocasiones no es posible encontrar las condiciones que permiten a las ciudades ser parte de su futuro, y en ese caso son otras las condiciones que provocan que las ciudades vean amenazada, incluso, su continuidad y su futura existencia.

La historia de Chile, fecunda en eventos desastrosos, ha mostrado en no pocas ocasiones el declive y hasta la desaparición de asentamientos humanos producto del efecto de una amenaza natural que se vuelca sobre centros poblados ubicados en zonas de riesgo: vale recordar el traslado del poblado de Penco hacia el Valle de la Isla Mocha (actual Concepción) producto del terremoto y tsunami de 1751 o la desaparición definitiva del Puerto de Cobija, en la Región de Antofagasta, luego de los terremotos de 1868 y 1877 . Son muchas las ciudades que en tiempos pasados no fueron capaces de enfrentar los grandes desastres, dando por terminada su historia.

En los tiempos actuales, son los fenómenos asociados al calentamiento global y el cambio climático los factores que están amenazando la supervivencia de poblados costeros alrededor de
1. Consultor, Banco Mundia, Washington D.C., EE.UU.

2. Fundación Proyecta Memoria, Concepción, Chile.

*Autor de correspondencia: victor.orellana.a@gmail.com

\section{RECIBIDO}

15 de mayo de 2019

\section{PUBLICADO}

1 de julio de 2019

\section{Formato cita}

Recomendada (APA): Orellana Acuña, V. (2019). El impacto de los desastres: Una oportunidad para crecer o desaparecer. Revista de Estudios Latinoamericanos sobre Reducción del Riesgo de Desastres REDER, 3(1), pp.113-116.

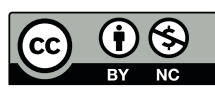

Todos los artículos publicados en REDER siguen una política de Acceso Abierto y se respaldan en una Licencia CreativeCommons Atribución-NoComercial 4.0 Internacional.

Revista de Estudios Latinoamericanos sobre Reducción del Riesgo de Desastres (REDER)

Diseño: Lupe Bezzina Tipografía: Hospital 
todo el mundo. El levantamiento del nivel del mar es uno de los peligros más concretos sobre, por ejemplo, los asentamientos ubicados en la costa de California, donde actualmente el $55 \%$ del área costera es altamente vulnerable a un aumento definitivo del nivel del mar de más de 1.5 metros, lo cual podría hacer desaparecer $2 / 3$ de las playas del sur de California hacia el año 2100 (Charles Lester, Marine Science Institute, Universidad de California, Santiago 2019). Una situación similar que se da en la zona opuesta de Estados Unidos como lo es New Orleans, donde actualmente se están midiendo tasas de hundimiento del nivel del suelo de hasta $5 \mathrm{cms}$. por año, producto de procesos geológicos que son agravados por la acción humana generada por la extracción de agua subterránea y la desecación de la superficie.

En países tan poderosos como Estados Unidos, esto empieza a ser un problema serio que seguramente compromete una serie de grandes obras de mitigación y contención de procesos que ya son irreversibles, pero a los que se les está dando pelea. Distinta es la situación de otras naciones menos favorecidas como Yakarta en Indonesia, donde recientemente se ha reportado que las tasa de hundimiento de su zona poblada podría llegar a un punto de no retorno que obligaría incluso al traslado de la capital política del país hacia una zona más segura para relocalizar a una población de más de 10 millones de personas. Así, los que hasta hace poco se reconocían como 'desastres lentos' están acelerando sus dinámicas hasta el punto que su avance se va haciendo cada vez más patente mientras las 'grandes decisiones' no son tomadas para revertir o por lo menos mitigar la nueva realidad. La adaptación al cambio climático, entonces, tiene un límite en el momento en que las condiciones de vida se hacen insostenibles para el asentamiento humano.

Volviendo al ámbito local, donde el peligro sísmico sigue siendo la componente más presente relacionada con el riesgo de desastre, la histórica sucesión de eventos (principalmente desde el siglo XX en adelante) ha significado un proceso permanente de aprendizaje, creación y asimilación de nuevo conocimiento. Esta dinámica hoy aparece como una constante que se ha manifestado por lo menos desde el terremoto de Valparaíso en 1906 hasta nuestros días: hoy nadie discute el valor de nuestra norma sísmica como un patrimonio construido a partir de sucesivos desastres por los cuales Chile ha tenido que pagar un alto costo, tanto en vidas humanas como en pérdidas materiales. Incluso los desagraciados eventos del terremoto y tsunami del 27 de Febrero de 2010 parecen hoy difíciles de repetirse dado el reconocido avance que todos los componentes del sistema de protección civil de Chile han alcanzado y que se han puesto a prueba (aunque en mucha menor medida) en los terremotos de 2014 y 2015.

Indudablemente, nuestro actual desarrollo económico nos ha permitido construir ciudades más robustas y más resilientes ante los desastres. En los últimos 40 años hemos generado una cantidad de riqueza que, aunque desigualmente distribuida, nos permite contar con capacidades adecuadas para enfrentar permanentemente el riesgo de grandes desastres, especialmente del tipo terremoto-tsunami. No obstante lo anterior, se instala la paradoja de que mientras más riqueza construimos, más riqueza ponemos en riesgo. El desarrollo de nuestros asentamientos costeros ha sido enorme desde el punto de vista económico, lo cual significa mayor población, edificaciones e infraestructuras expuestas a las mismas antiguas y permanentes amenazas. El riesgo entonces ha aumentado, y no sabemos si lo ha hecho en una proporción que esté al alcance de nosotros poder enfrentar. Escenarios de riesgo como el que se está configurando en la zona costera de la Región de Valparaíso, donde se concentra más del $80 \%$ de nuestra capacidad portuaria (San Antonio y Valparaíso) además de una industria turística de alcance continental (Valparaíso y Viña del Mar), y con una ventana de silencio sísmico de varias decenas de años, nos ubican en una situación muy parecida ( guardando las proporciones) a lo ocurrido en Kobe en el año 1995, donde un desastre de gran magnitud podría enfrentarnos a un duro golpe en nuestro desarrollo económico y capacidad competitiva a escala continental y global. Un golpe tan grande que determine el fin de nuestra principal metrópoli portuaria.

En los próximos años, podríamos vernos enfrentados nuevamente a la desaparición de ciudades completas por causa de los desastres. ¿Qué tan preparadas están nuestras ciudades? ¿Serán suficientemente resilientes a los nuevos desafíos? ¿Podemos anticiparnos? El futuro seguramente no está garantizado, sin embargo podríamos encontrar ciertas claves de éxito en casos como el de la ciudad de Talcahuano (Región del Biobío), el que luego del duro trance sufrido por el terremoto del 2010 hoy está situado muy cerca de las 10 ciudades con mejor calidad de vida urbana de Chile, según el Índice de Calidad de Vida Urbana (ICVU) del 2019. 


\section{EL CASO DE TALCAHUANO}

Talcahuano fue considerado por mucho tiempo como 'el patio trasero' de Concepción. Un territorio natural complejo donde interactúan distintos actividades industriales (pesca, hidrocarburos, siderurgia), un aeropuerto, una base naval, dos puertos y una población distribuida entre zonas planas y cerros. Todos estos usos de suelo urbano se vinculan en una dinámica no exenta de tensiones, sobre un paisaje de alta fragilidad que de vez en cuando entraba en crisis ambientales que en alguna oportunidad incluso la situaron entre las bahías más contaminadas del mundo. Este ambiente de gran complejidad y permanente conflicto ambiental, se superponía a un entorno socio-económico rezagado, producto de las crisis sucesivas de las industrias locales. En este contexto, el advenimiento del terremoto y posterior tsunami del 27 de febrero de 2010 se encargó de agravar el cuadro pre-existente de precariedad ambiental y social, planteando un horizonte de recuperación post desastre de una amenazante complejidad y difícil resolución.

Fueron los primeros sentimientos de orgullo local los que empezaron a configurar un cuadro de cohesión social que sirvió de base a una campaña de recuperación colectiva liderada desde el gobierno local y que se enfrentaba al centralismo en la toma de decisiones de una reconstrucción que los ponía en una posición secundaria, por detrás de la capital regional (Concepción). Permanecía, incluso después del gran desastre, un capital social movilizador que consiguió alinearse en búsqueda de un proceso de reconstrucción que devolviera la dignidad perdida, entregando una chispa de esperanza a una comunidad que se organizó en la convicción de exigir la reconstrucción de un 'Nuevo Talcahuano'.

El proyecto de recuperación del borde costero de la ciudad de Talcahuano, en el sector de La Poza, fue por lejos la obra más emblemática de este proceso, tanto por su calidad en el diseño como por los nuevos espacios públicos que entregaba a los ciudadanos. Se construyó y consolidó un espacio de gran funcionalidad urbana pero también de un alto valor simbólico por lo que significa recuperar para los ciudadanos un espacio que le entregó una nueva cara a la ciudad, más abierta y adecuada a una ciudad que vio en el proceso de reconstrucción post terremoto una oportunidad de resolver inequidades históricas. Esta acción sumada a otras, llevó a que los índices de calidad urbana (ICVU) subieran sostenidamente desde el año 2014 en adelante, donde si bien no son resultados comparables entre sí, la ciudad de Talcahuano subió desde el lugar 65 (2014) al 11 (2019). Finalmente, el regreso de los cruceros turísticos europeos a partir del año 2016, terminaron por consolidar a Talcahuano como un ejemplo reconocido a nivel internacional de un proceso de reconstrucción post desastre que, más allá de las pérdidas sufridas, fue entendido como una oportunidad de desarrollo local y sostenible. Talcahuano hoy es una ciudad renovada.

\section{CONCLUSIONES}

El concepto de renovación post desastre considera una serie de procesos que, articulados de manera correcta, pueden ayudar a que el resultado final signifique una ganancia de valor, es decir una mejora de la tendencia histórica que la ciudad venía desarrollando antes del advenimiento del desastre. En el caso de una ciudad como Talcahuano ha significado resolver una condición histórica de vulnerabilidad social y ambiental.

Este desafío de 'Reconstruir Mejor' o build back better puede ser incluso una orientación para analizar y proyectar escenarios de riesgo en áreas actualmente expuestas y vulnerables, determinando anticipadamente medidas que consigan mitigar los efectos inmediatos de un desastre y, junto con ello, reducir los impactos de mediano y largo plazo en la sociedad y la economía. En la medida que se logre dimensionar y evaluar el riesgo de un potencial desastre sobre un lugar o una comunidad determinada, será posible anticipar acciones que en su conjunto ayudarán a fortalecer su resiliencia. Tomar estas medidas de análisis y acción de manera previa al potencial desastre puede significar la diferencia entre crecer o desaparecer.

Finalmente, la experiencia (positiva o negativa) de localidades tan distintas como Kobe, Penco, Cobija, California, New Orleans, Yakarta, Valparaíso, San Antonio, Viña del Mar, Concepción o Talcahuano va entregando pistas que podrían servir como marco de análisis de la condiciones predictoras o gatilladoras de un proceso de reconstrucción exitoso o fallido en el corto, mediano y largo plazo:

1. Fortaleza y liderazgo del gobierno local para canalizar procesos de cambio.

2. Identificación de los riesgos del entorno y comprensión del medio desde el punto de vista de las amenazas y vulnerabilidades. 
3. Patrimonio cultural y social con base en la memoria de los desastres pasados.

4. Cohesión comunitaria para construir una visión colectiva de futuro.

5. Coordinación y articulación entre niveles de gobierno (comunal-regional-nacional) y asociación público-privada. 